\title{
Fen Alanları Öğretmen Adaylarının Akademik Erteleme Davranışları ile Eğitim Teknolojilerine Yönelik Tutumları Arasındaki İlişki
}

\author{
Hülya ASLAN EFE1 \\ 1 Yrd.Doç.Dr.,Dicle Üniversitesi, Ziya Gökalp Eüitim Fakültesi, Fen Bilgisi Ögrretmenliği ABD, bulyaefe@dicle.edu.tr
}

DOI: http://dx.doi.org/10.14582/DUZGEF.707

$\mathrm{Bu}$ araştırmanın amacı fen alanları öğretmen adaylarının akademik erteleme davranışlarının eğitim teknolojilerine yönelik tutumlarından ne derece etkilendiğini ortaya koymaktır. Araştırmaya 2011-2012 eğitim öğretim yllında öğrenim gören 535 (K:357, E:181) fen alanı öğretmen adayı katılmıştır. Veriler çoklu regresyon kullanılarak analizi edilmiştir. Araştırmada very toplama aracı olarak "Eğitim Teknolojilerine Yönelik Tutum" ve "Akademik Erteleme Olçeği” kullanılmıștır. Araștırmanın sonunda akademik erteleme davranışı ile teknoloji kullanma sıklığı ve teknolojik alt yapı değişkenleri arasında negatif yönlü bir ilişki olduğu belirlenmiştir.

Anahtar Kelimeler: akademik erteleme, eğitim teknolojileri, tutum, fen alanları öğretmen adayları

\section{The Relationship Between Academic Procrastination Behaviors of Preservice Science Teachers and Their Attitudes Toward Educational Technology}

\begin{abstract}
In this study, the relationship between study preservice science teachers' academic procrastination and their attitudes toward educational technology was investigated. The sample of the study involved 538 (F: 357, M:181) preservice science teachers in a teacher education course during the 2011-2012 academic year. The date was collected through "Attitudes Towards Educational Technology Scale" and "Academic Procrastination Scale". The data were analyzed using Multiple Linear Regression. The results of study showed that there is negative correlation between academic procrastination, technology using frequency and tecnology back ground variables.
\end{abstract}

Key Words: Academic Procrastination, Educational Technology, Attitude, Science Preservice Teachers

\section{GİRİŞ}

Birçok insan, sorumluluklarını zamanında gerçekleştiremediklerinden ötürü sıkıntı yaşamaktadırlar. Sınavlarına son gece çalışan, ödevlerini son gün alelacele yetiştirmeye kalkışan, ödenmesi gereken faturalanı zamanında ödemeyen, düzenli spor yapmaya niyetlendiği halde bunu bir türlü gerçekleştiremeyen, sağlık sorunlarından ötürü hastaneye gitmesi gereken fakat bunu sürekli ileri bir tarihe atan kişiler bulunmaktadır. İnsanlar söz konusu bu davranışlarından ötürü rahatsızlık duymakla birlikte, bir daha bunu yapmayacaklarına dair kendilerine söz verseler bile kendilerini aynı kısır döngü içinde bulmaktadırlar (Burka \& Yuen, 1983). Alanyazında bu davranışların tümü "erteleme davranışı" olarak tanımlanmaktadır. Knaus (1998) erteleme davranışını, zamanında yapılması gereken ve önceliği olan bir işi gereksiz yere geciktirme ya da son ana bırakma olarak tanımlamaktadır. Steel (2002), ise ertelemeciliği, kişinin verimini en üst düzeye çıkarmasını engelleyeceğini bilmesine rağmen, istemli olarak yapılan bir eylem olarak açıklamaktadır. Erteleme davranışının nedenlerine ait alan yazındaki araştırmalar incelendiğinde, eğitim alanında çalışan uzmanların, son dönemlerde akademik erteleme konusu üzerinde yoğunlaşarak, akademik erteleme davranışının olası nedenlerini ortaya 
çıkarmaya çalıştkları görülmektedir (Akinsola, Tella \& Tella, 2007; Dietz, Hofer \& Fries; 2007; Hen \& Goroshit; 2014). Çünkü akademik erteleme davranışı, erteleme yapan öğrencinin akademik başanısızlık yaşaması, zor derslerden geri kalması, devamsızlık yapması ve hatta okulu bırakması gibi olumsuz sonuçlar doğurmaktadır (Knaus, 1998). Akademik erteleme davranışı, sınava hazırlanma, dönem ödevi hazırlama, okulla ilgili idari işler, katılım görevi gibi temel akademik görevlerin belli nedenlerle geciktirilmesi olarak tanımlanmaktadırlar (Solomon \& Rothblum, 1984). Illgili alanyazında, akademik ertelemenin üniversite öğrencileri arasında sık görülen bir davranış olduğu ve hem üniversite öğrencilerinde hem de mezunlarında yaygınlı̆̆ının \%20 ile \%95 arasında değiştiği vurgulanmaktadır (Charlebois, 2007). Türkiye'de yapılan bir çalışmada lise ve lisans öğrencilerinin \% 53'ünün, lisansüstü öğrencilerinin \% 61’inin sıklıkla erteleme davranış1 içerisinde bulunduğu belirlenmiştir (Uzun Özer, 2011). Clark \& Hill (1994), 194 üniversite öğrencisi üzerinde yaptıkları çalışmada, üniversite öğrencilerinin erteleme davranışı sıklıklarını akademik erteleme alanlarına göre incelemiş ve üniversite öğrencilerinin \%28'inin sınavlara hazırlamada, \%30'unun dönem ödevi yazmada ve \%36'sının da haftalık okuma ödevlerini yapmada erteleme davranışı gösterdiklerini belirtmişlerdir. Ouwuegbuzie (2004) ise, üniversite öğrencilerinin \%42'sının dönem ödevini hazırlamada \%39'unun sinavlara hazırlanmada ve \%60'ının haftalık okumalarını yapmada erteleme davranışı gösterdiklerini rapor etmişlerdir. Bir diğer çalışmada da, üniversite öğrencilerinin \%46'sının ödev hazırlamada, \%28'inin sınavlara hazırlanmada ve \%30'unun haftalık okumalarını yapmada erteleme davranışı gösterdikleri bulgusunu elde etmişlerdir (Solomon \& Rothblum, 1984). Akademik erteleme davranışının üniversite öğrencileri arasında yaygın olması alanyazında pek çok değişkenle ilişkili bulunması ile kendini göstermektedir. Dolayısıyla, üniversite öğrencilerinin akademik erteleme davranışlarının artmasında ya da azalmasında rol oynayan faktörlerin belirlenmesi büyük önem taşımaktadır. Akademik erteleme davranışını inceleyen çalışmadan bazıları, hoşa giden faaliyetlerden biri olan teknoloji kullanımının akademik görevlerin bitimine engel olabileceği sonucuna ulaşmışardır (Ellis \& Knaus, 1977; Schouwenburg, 2004). Milgram (1992), teknolojinin ilerlemiş olduğu toplumlarda erteleme davranışının yaygın olduğuna işaret etmektedir. Üniversite öğrencilerinin eğlenceli olmayan ve zor olarak algıladıkları akademik görevler ile aktif olarak meşgul olmadıkları, bunun yerine televizyon izleme, elektronik posta bakma, internette gezinme gibi teknolojik etkinlikler ile meşgul olduklan görülmüştür (Milgram, Mey-Tal \& Levison, 1998; Klassen v.d. 2010, Schouwenburg, 2004). Nitekim öğretmenlerin teknoloji kullanımı ile akademik erteleme arasında pozitif yönlü bir ilişkinin mevcut olduğu alanyazında yer almaktadır (Kızılkaya Cumaoğlu \& Diker Coşkun, 2012). Bu nedenle öğretmen adaylarının, öğrencilik hayatları boyunca kullandıkları ve mesleğe atıldıktan sonra da sıklıkla kullanacakları eğitim teknolojilerine yönelik tutumlarının akademik erteleme davranışlarını etkileme düzeyleri merak konusudur. Teknolojinin pek çok alanda olduğu gibi çeşitli eğitim kademelerindeki okullarda da hızla kullanımının yaygınlaştı̆̆1 ve eğitim-öğretim sistemlerinin ayrılmaz birer parçaları olduğu göze çarpmaktadır. Eğitimde teknoloji kullanımının önemi arttıkça öğretmen ve öğrencilerin sınıf ortamında teknoloji kullanımına yönelik tutumları daha önemli hale gelmekte ve teknolojiye yönelik tutum çalısmaları eğitim alanında yapılan bilimsel çalışmalardaki yerini arttırmaktadır. Heinssen, Glass \& Knight (1987), teknoloji tutumunu kişinin teknolojiyi ne ölçüde anladığ1 ve bilgi teknolojilerinin toplum ve yaşam kalitesi üzerindeki etkisi hakkındaki görüşleri olarak ifade etmektedir. Alan yazına bakıldığında öğretmenlerin, öğretmen adaylarının ve öğrencilerin teknolojiye yönelik tutumları birçok çalışmada farklı değişkenler açısından incelenmiştir (Almahboud 2000, Asan 2002, Apay \& Özbaşı 2008). Teknoloji kullanımının akademik ertemeleme üzerine etkilerini web tabanlı dersler ve uzaktan eğitim bağlamında işleyen araştırmalar mevcut olsa da (Humprey \& Harbin, 2010), gerek öğretim ortamında gerekse öğretim ortamı dışında teknoloji ile meşgul olan geleceğin öğretmenlerinin eğitim teknolojilerine yönelik tutumlarının akademik erteleme davranışlarını etkilenme boyutu ile ilgili bir araştırmaya rastlanmamıştır. Bu bağlamda, bu araştırmada, geleceğin fen alanları öğretmenlerinin akademik erteleme davranışlanının, teknoloji kullanma sıklığı, teknolojiye erişim olanağı, teknolojik alt yapı, eğitim teknolojilerini ileride öğrencilerine kullandırmaya yönelik tutum, eğitim teknolojilerini ileride sınıf ortamında kullanmaya 
yönelik tutum ve eğitim teknolojilerinin öğretime kattı̆̆1 değere yönelik tutum değişkenleri ile açıklanabilirliğinin incelenmesi amaçlanmaktadır.

\section{YÖNTEM}

Araştırma da yöntem olarak betimsel tarama modelinde karşılaştırma türü ilişkisel tarama kullanılmıştır. Tarama yöntemi, geçmişte veya halen var olan bir durumu var olduğu şekliyle betimlemeyi amaçlayan araştırma yaklaşımıdır. Genel tarama modellerinden ilişkisel tarama modellerinde ise, iki ve daha çok sayıdaki değişken arasında birlikte değişim varlığını ve derecesinin belirlemesi amaçlanmaktadır. İlişkisel tarama modelinde aralarında ilişki aranacak değişkenler ayrı ayrı sembolleştirilir. Ayrıca bu sembolleştirme ilişkisel bir çözümlemeye olanak verecek şekilde yapılmaktadır (Karasar, 2000).

\subsection{Katılımcilar}

Bu araştırmaya, 2011-2012 eğitim öğretim yllında fizik, kimya, biyoloji ve fen bilgisi öğretmenliği anabilim dallarında öğrenim gören 538 öğretmen adayı katılmıştır. Araştırmanın verileri bahar dönemi boyunca toplanmıştır. Araştırmaya katılan fen alanları öğretmen adaylarının 357’si kız, 181’i ise erkektir.

\subsection{Veri toplama araçları}

Araştırmada tutum ölçeği olarak Efe (2011) tarafindan İngilizce olarak geliştirilen "Fen Bilgisi Öğretmen Adaylarının Eğitim Teknolojisi Anketi" kullanılmıştır. Likert tipi olan anket, dört boyut ve 48 maddeden oluşmaktadır. Araştırmada anketin birinci alt boyutu olan eğitim teknolojileri alt yapısı "hiçbir zaman”, "çok az", "bazen", "sık sık" ve "her zaman" olarak derecelendirilmiştir. Anketin ikinci alt boyutu olan eğitim teknolojilerini ileride öğrencilere kullandırmayı düşünme boyutu "fikrim yok/bilmiyorum”, "hiçbir zaman”, “çok az”, "bazen”, “sık sık” ve "her zaman” olarak derecelendirilmiştir. Anketin üçüncü alt boyutu olan eğitim teknolojilerini ileride kullanmayı düşünme boyutu ise “fikrim yok/bilmiyorum”, “negatif”, “etkisiz”, “düşük etkili”, "olumlu” ve "çok olumlu” olarak derecelendirilmiştir. Anketin dördüncü alt boyutu olan eğitim teknolojilerinin fen öğretimine olan katkısı boyutu "fikrim yok/bilmiyorum", "hiçbir zaman”, "çok az", "bazen”, "sık sık" ve "her zaman” olarak derecelendirilmiştir. Anket yazar tarafindan Türkçe'ye çevrilmiştir. Çeviri işleminden sonra anket İngilizce Öğretmenliği ABD’nda görev yapan 4 öğretim elemanı tarafindan incelenmiştir. Gerekli düzeltmeler yapıldıktan sonra iki öğretmen adayı ile karşılıklı görüşme yapılmış ve anketin uygulanabilirliğine karar verilmiştir. Anketin faktör analizi sonucunda ölçeğin Kaiser-Meyer-Olkin (KMO) değeri .912, ve Küresellik değeri Bartlett Testi 10395,957 (DF:1128, p: .000) olarak hesaplanmıştur. Faktör analizi sonucunda Eigen değeri 1'den yüksek olan 10 faktör ortaya çıkmasına rağmen 4 faktörün varsanslar1 toplamının $(\% 22,979, \% 11,024, \% 6,782$ ve $\% 3,978)$ toplam varyansın $\% 44,762$ olduğu görülmüştür. Kline (1994) ve Tabachnick ve Fidell (1998) yaptıkları hesaplamalarda varyansın tüm varyansın \%41'ni açıklayabilmesi yeterli görülmüştür. Anketin güvenilirliği anketi Cronbach alpha ile belirlenmiştir. Bu araştırmada ölçeğin tamamı için Cronbach alpha 0,93 olarak belirlenmiştir. Anketin alt boyutları için ise birinci, ikinci, üçüncü ve dördüncü boyutlar için Cronbach alphalar sırasıyla $.91, .87, .85$ ve .88 olarak bulunmuştur.

Fen alanları öğretmen adaylarının akademik erteleme davranışlarını belirlemek amacıyla Çakıcı (2003) tarafından geliştirilen 19 maddeden oluşan "Akademik Erteleme Ölçeği" kullanılmıştır. Ölçekten alınan yüksek puan bireyin ertelemeci olduğunu göstermektedir. Ölçek tek boyutlu olarak kullanılmaktadır. Akademik erteleme ölçeğinin Cronbach alpha güvenirlik katsayısı Çakıcı (2003) tarafından 92 olarak bulunmuştur. Bu araştırma için ölçeğin Cronbach alpha güvenirlik katsayısı .85 olarak bulunmuştur.

\subsection{Verilerin Analizi}

Araştırmanın verileri toplandıktan sonra, teknoloji kullanım sıklığı, erişim olanağı, eğitim teknolojileri alt yapısı, eğitim teknolojililerini ileride öğrencilerine kullandırmaya yönelik tutum, ileride kullanmaya yönelik tutum ve fen öğretimine kattığı değere yönelik tutum değişkenlerinin akademik erteleme davranışını ne derece yordadıklarını belirlemek için çoklu doğrusal regresyon analizi kullanılmıştır. Analiz yapılmadan önce çoklu 
doğrusal regresyon analizinin varsayımları test edilmiştir. Çoklu doğrusal regresyon analizinin normallik ve doğrusallık varsayımlarının karşılandığı belirlenmiştir. Tolerans, VIF ve Durbin-Watson değerleri kabul edilir sınırlar içindedir.

\section{BULGULAR}

Bu bölümde fen alanları öğretmen adaylarının eğitim teknolojilerine yönelik tutumlarının akademik erteleme davranışları üzerine etkisi belirlenmiştir.

Teknoloji kullanım sıklı̆̆, teknolojiye erişim olanağı, teknolojik alt yapı, eğitim teknolojilerini ileride öğrencilerine kullandırmaya yönelik tutum, eğitim teknolojilerini ileride kullanmaya yönelik tutum ve eğitim teknolojilerinin fen öğrenmeye katkısı değişkenlerinin akademik erteleme davranışının yordanmasına ilişkin regresyon analiz sonuçları tablo 1'de verilmiştir. Yordayıcı değişkenlerle yordanan değişken arasındaki ikili ve kısmi korelasyonlar incelendiğinde teknoloji kullanma sıklı̆̆ ile akademik erteleme arasında negatif ve düşük düzeyde bir ilişkinin $(r=-0,016)$ olduğu, ancak diğer değişkenler kontrol edildiğinde iki değişken arasındaki korelasyonun $r=-0,055$ olduğu hesaplanmıştır. Buna karşın, teknolojiye erişim olanağı ile akademik erteleme arasında ise pozitif ve düşük düzeyde bir ilişki $(\mathrm{r}=0,061)$ tespit edilmiştir.

Tablo 1. Akademik ertelemenin yordanmasına ilişkin çoklu regresyon analizi

\begin{tabular}{|c|c|c|c|c|c|c|c|c|}
\hline Bağımlı Değiş̧ken & Yordayıc1 Değişkenler & B & $\begin{array}{l}\text { Standart } \\
\text { Hata }\end{array}$ & $\beta$ & $\mathrm{t}$ & $\mathrm{p}$ & İkili & Kismi \\
\hline \multirow{4}{*}{ Akademik } & Sabit & 2,559 & 0,275 & - & 9,293 & $0,000^{*}$ & - & - \\
\hline & Teknoloji Kullanma & $-0,032$ & 0,025 & $-0,067$ & $-1,271$ & 0,204 & $-0,016$ & $-0,055$ \\
\hline & S1klığ1 & & & & & & & \\
\hline & Erişim olanağ1 & 0,077 & 0,041 & 0,100 & 1,868 & 0,062 & 0,061 & 0,081 \\
\hline \multirow{12}{*}{ Erteleme } & Teknolojik Altyap1 & $-0,027$ & 0,042 & $-0,031$ & $-0,646$ & 0,519 & $-0,018$ & $-0,028$ \\
\hline & Eğitim Teknolojilerini & 0,095 & 0,046 & 0,127 & 2,079 & $0,038^{*}$ & 0,118 & 0,090 \\
\hline & İleride Öğrencilerine & & & & & & & \\
\hline & Kullandırmaya Yönelik & & & & & & & \\
\hline & Tutum & & & & & & & \\
\hline & Eğitim Teknolojilerini & 0,030 & 0,046 & 0,038 & 0,665 & 0,506 & 0,093 & 0,029 \\
\hline & İleride Kullanmaya & & & & & & & \\
\hline & Yönelik Tutum & & & & & & & \\
\hline & Eğitim Teknolojilerinin & $-0,066$ & 0,050 & $-0,066$ & $-1,335$ & 0,183 & 0,008 & $-0,058$ \\
\hline & Fen Öğretimine Katkısı & & & & & & & \\
\hline & $\mathrm{R}^{2}=0,026$ & & & & & & & \\
\hline & $\mathrm{F}=2,333 \quad \mathrm{p}=0,031^{*}$ & & & & & & & \\
\hline
\end{tabular}

Yordayıcı değişkenlerle yordanan değişken arasındaki ikili ve kısmi korelasyonlara bakıldığında, eğitim teknolojilerine yönelik tutum alt boyutlarından teknolojik alt yapı ile akademik erteleme davranışı arasında negatif ve düşük düzeyde bir ilişkinin $(\mathrm{r}=-0,018)$ olduğu, ancak diğer değişkenler kontrol edildiğinde iki değişken arasındaki korelasyonun $r=-0,028$ olarak hesaplandığı görülmektedir. Fakat eğitim teknolojilerine yönelik tutum boyutlarından ileride öğrencilerine kullandırma ile akademik erteleme davranışı arasında hesaplanan pozitif ve düşük düzeyde ikili korelasyonun ( $\mathrm{r}=0,118)$, diğer beş değişken kontrol edildiğinde de, pozitif ve düşük düzeyde $(\mathrm{r}=0,09)$ olduğu görülmektedir. Eğitim teknolojilerine yönelik tutum boyutlarından ileride kullanmaya yönelik tutum ile akademik erteleme davranışı arasında pozitif ve düşük düzeyde $(r=0,093)$ bir ilişki vardır. Ancak diğer değişkenler kontrol edildiğinde, bu korelasyonun $r=0,029$ olarak hesaplandığ1 görülmektedir. Benzer olarak, eğitim teknolojilerinin fen öğretimine katkısı ile akademik erteleme davranışı arasında pozitif ve düşük düzeyde bir ilişkinin olduğu $(\mathrm{r}=0,008)$, ancak diğer beş değişken kontrol edildiğinde de, negatif ve düşük düzeyde $(r=-0,058)$ bir ilişkinin olduğu belirlenmiştir. 
Teknoloji kullanım sılklğı, erişim olanağı, teknolojik alt yapı, öğrencilere kullandırma, ileride kullanma ve fen öğretimine katkı değişkenleri birlikte fen alanları öğretmen adaylarının akademik erteleme davranışları ile düşük düzeyde ve anlamlı bir ilişki vermektedir $\left(R=0,160, R^{2}=0,026, p<0,05\right)$. Adı geçen dört değişken birlikte, akademik erteleme davranışındaki toplam varyansın yaklaşık \%3’ünü açıklamaktadır.

Standardize edilmiş regresyon katsayısına $(\beta)$ göre, yordayıcı değişkenlerin akademik erteleme üzerindeki göreli önem sırası; öğrenciye kullandırma $(\beta=0,127)$, erişim olanağ1 $(\beta=0,100)$, kullanım sıklığı $(\beta=-0,067)$, fen öğretimine katk1 $(\beta=-0,066)$, ileride kullanma $(\beta=0,038)$ ve teknolojik alt yapıdır $(\beta=-0,031)$. Regresyon katsayılarının anlamlılığına ilişkin t-testi sonuçları incelendiğinde ise ileride öğrencilere kullandırma değişkeninin akademik erteleme davranışı üzerinde pozitif yönlü ve anlamlı bir yordayıcı olduğu görülmektedir.

\section{TARTIŞMA}

$\mathrm{Bu}$ araştırmanın sonucunda fen alanları öğretmen adaylarının teknoloji kullanma sıklıkları arttıkça akademik erteleme davranışlarının azaldığı belirlenmiştir. Bu sonuca, teknoloji kullanımı ile akademik işlerin çok daha kısa sürede tamamlanmasından dolayı ulaşılmış olabilir. Nitekim yaşamımızın hemen her alanına girmiş olan bilişim teknolojilerinin, günlük ve akademik faaliyetlerimizi gerçekleştirmedeki desteği yadsınamayacak derecede büyüktür (Sarıtaş \& Üner, 2013). Özellikle eğitim teknolojilerinden bilgisayarların, veriye ulaşmada, veri işlemede ve veri saklamada kolaylık sağlaması, günün 24 saatinde çalışabilir olması, sürekli tekrarı gerektiren işleri tekrardan kurtarması, taşınabilir olması ve gittikçe ucuzlamasından dolayı akademik işlerin kısa sürede yapılması yönünde avantaj sağladığı söylenebilir (Altun, 2002). Araştırmada, teknolojiye erişim olanağı arttıkça akademik ertelemenin arttığ1 belirlenmiştir. Teknolojiye kolay ulaşımın eğlence amaçlı teknoloji kullanımını desteklediği söylenebilir. Özellikle günümüzde herkesin kolaylıkla sahip olabileceği cep telefonlanı, öğrencileri aşırı meşgul etmektedir (Çetin, Pamuk \& Durmuş, 2015). Öğrenciler teknoloji ile meşgul iken zamanın nasıl aktığının farkında olmama durumu ile karşı karşıya kalırlar. Zamanı etkili şekilde kullanamama durumu ise akademik erteleme davranışına neden olmaktadır (Ferrari vd., 1997). Pychyl, Lee, Thibodeau \& Blunt (2000) tarafindan yakın zamanda yapılan araştırmada, zevk veren kısa süreli ve özel ödüllerin olduğu etkinliklerin erteleme davranışına yön verdiğini vurgulamaktadırlar. Araştırmanın bir diğer sonucu, fen alanları öğretmen adaylarının eğitim teknolojileri alt yapıları ne kadar güçlüyse akademik erteleme düzeylerinin o kadar düşük olduğuna işaret etmektedir. Bu durum teknolojik alt yapısı güçlü kişilerin teknoloji ile akademik işler arasında işlevsel bir denge kurabilmelerinden kaynaklanıyor olabilir. Ayrıca araştırmada, fen alanları ögretmen adaylarının eğitim teknolojilerini ileride öğrencilerine kullandırmaya yönelik tutumları ile akademik erteleme davranışları arasında pozitif bir ilişkinin olduğu belirlenmiştir. Benzer olarak, fen alanları ögretmen adaylarının eğitim teknolojilerini ileride kullanmaya yönelik tutumları ile akademik erteleme davranışı arasında da pozitif yönlü bir ilişkinin varllğı tespit edilmiştir. Nitekim Kızılkaya Cumaoğlu \& Diker Çoşkun (2012) çalışmalarında sınıf ortamında eğitsel video kullanan öğretmenlerin akademik erteleme davranışlanının daha yüksek olduğuna vurgu yapmaktadırlar. Teknoloji kullanım sıklı̆̆1, erişim olanağı, teknolojik alt yapı, öğrencilere kullandırma, ileride kullanma ve öğretime katkı değişkenleri birlikte fen alanları öğretmen adaylarının akademik erteleme davranışlan ile düşük düzeyde ve anlamlı bir ilişki vermektedir ve adı geçen dört değişken birlikte, akademik erteleme davranışındaki toplam varyansın yaklaşık \%3’ünü açıkladığ1 tespit edilmiştir. Yordayıcı değişkenlerin akademik erteleme üzerindeki göreli önem sırası; öğrenciye kullandırma, erişim olanağı, kullanım sıklığ1, fen öğretimine katk1, ileride kullanma ve teknolojik alt yapı olduğu belirlenmiştir.

\section{5. ÖNERİLER}

Araştırmanın sonunda fen alanları öğretmen adaylarının eğitim teknolojilerine yönelik tutumları ile akademik erteleme davranışları arasında düşükte olsa anlamlı bir ilişkinin olduğu tespit edilmiştir. Bu bağlamda fen alanları öğretmen adaylarının eğitim teknolojilerine yönelik tutumlarından kaynaklanan akademik erteleme davranışlanını azaltmaya yönelik grup çalışmaları ya da deneysel araştırma programları geliştirilerek 
uygulanabilir. Ayrıca buna benzer çalışmalar ilk ve ortaöğrenim düzeyinde öğrenim gören öğrenciler üzerinde yapılabilir. Bu dönemde yapılması daha yararlı olabilir. Bu yolla öğrencilerin ders çalışma ve zamanı yönetme konusunda bilgilendirilmeleri ve bu konuda desteklenmeleri onların alışkanlıklarını değiştirebilir ve bu olumlu alışkanlıkları daha kalıcı hale gelebilir. Bu da üst öğrenim kademelerinde onların daha az erteleme sorunu yaşamalarına neden olabilir.

\section{KAYNAKÇA}

Akinsola, M.K., Tella, A. \& Tella, A. (2007). Correlates of Academic Procrastination and Mathematics Achievement of University Undergraduate Students. Eurasia Journal of Mathematics, Science \& Technology Education, 3(4), 363-370

Almahboub. S.F. (2000). Attitudes toward computer use and gender differences among kuwaiti sixth-grade students. (Doktora Tezi). University of North Texas. 06.09.2012 tarihinde ilgili siteden indirilmiştir. http://digital.library.unt.edu/ark:/67531/metadc2663/m2/1/high res d/Dissertation.pdf

Altun, S.A. (2002). Okul yöneticilerinin teknolojiye karşı tutumlarının incelenmesi. Çă̆daş Eğitim, 286 . 8-14.

Asan, A. (2002). Fen ve sosyal alanlarda öğrenim gören öğretmen adaylarının bilgisayara yönelik tutumları. Eğitim Araştırmalar Dergisi, 7(1): 136-146.

Aypay, A. \& Özbaşı, D. (2008). Öğretmenlerin bilgisayara karşı tutumlarının incelenmesi. Kuram ve Uygulamada Ë̈itim Yönetimi, 55: 339-362

Burka, J. B., \& Yuen, L. M. (1983). Procrastination: Why you do it, what to do about it. Reading, MA: AddisonWesley

Charlebois, K. J. (2007). Doing tomorrow what could be done today: An investigation of academic procrastination. (Unpublished doctoral dissertation), Boston College Boston, USA.

Clark, J. L., \& Hill, O. W. (1994). Academic procrastination among African-American college students. Psychological Reports, 75, 931-936

Efe, R. (2011). Science student teachers and educational technology: experience, intentions, and value. Educational Technology Society, 14 (1): 228-240.

Kızılkaya Cumaoğlu, G. \& Diker Coṣkun, Y. (2012). Öğretmenlerin Akademik Erteleme Davranışı ile Teknoloji Kullanım Durumları Arasindaki İlişki, International Periodical For The Languages, Literature And History of Turkish or Turkic, v.7/4, p.2237-2247,

Çakıc1, D. C.. (2003). Lise ve üniversite ögrencilerinde genel erteleme ve akademik erteleme davranısınn incelenmesi. (Yayınlanmamış Yüksek Lisans Tezi), Ankara Üniversitesi, Ankara.

Dietz, F., Hofer, M., \& Fries, S., (2007). Individual values, learning routines and academic procrastination. British Journal of Educational Psychology, 77(4), pp.893-906.

Ellis, A., \& Knaus, W.J. (1977). Overcoming procrastination. New York: New American Library

Ferrari, J.R. (2010). Still procrastinating? The no regret guide to getting it done. New York. J.Wiley \& Sons, Inc

Heinssen, R. K., Glass, C. R., \& Knight, L. A. (1987). Assessing computer anxiety: Development and validation of the computer anxiety rating scale. Computers in Human Bebavior, 3, 49-59.

Hen, M. \& Goroshi, M. (2014) Academic self-efficacy, emotional intelligence, gpa and academic procrastination in higher education. Eurasian Journal of Social Sciences, 2(1), 2014, 1-10

Humprey, P. \& Harbin, J. (2010). An explaratory study of the effect of rewards and deadlines on academic procrastination in web-based classes. Academy of Educational Leadership Journal, 14(4), 91-98.

Knaus, W.J. (1998). Do it now! Break the procrastination habit. New York: John WileyveSons, Inc.

Karasar, N. (2000). Bilimsel arastırma yöntemi. Ankara: Nobel Yayın Dağıtım

Klassen, R.M., Ang, R.P., Chong, W.H., Krawchuk, L.L., Huan, V.S., Wong, I.Y.F. \& Yeo, L.S. (2010). Academic Procrastination in Two Settings: Motivation Correlates, Behavioral Patterns, and Negative Impact of Procrastination in Canada and Singapore. Applied psychology: An International Review, 59 (3), 361-379

Milgram, N. A. (1992). El retraso: Una enfermedad de los tempos modernos [Procrastination: A malady of modern time]. Boletin de Psicologia, 35,83-102

Milgram, N, Mey-Tal, G. \& Levison, Y. (1998). Procrastination, generalized or specific, in college students and their parents. Personality and Individual Differences, 25, 297-3 16.

Onwuegbuzie, A. J. (2004). Academic procrastination and statistics anxiety. Assessment ve Evaluation in Higher Education, 29 (1), 3-19.

Pychyl, T.A., Lee, J.M., Thibodeau, R. \& Blunt,A. (2000). Five days of emotion: An experience sampling study of under graduate student procrastination [Specialissue]. Journal of Social Behavior and Personality, $15,239-254$ 
Sarıtaş, M. T. \& Üner, N. (2013). Eğitimdeki Yenilikçi Teknolojiler: Bulut Teknolojisi. Eğitim ve Öğretim Arastırmalar Dergisi, 2(3)

Schouwenburg, H. C. (2004). Academic procrastination: Theoretical notions, measurement, and research. In H. C. Schouwenburg, C. H. Lay, T. A. Pychyl, \& J. R. Ferrari (Eds.), Counseling the procrastinator in academic settings (pp. 3-17). Washington, DC: American Psychological Association.

Solomon, L. J., \& Rothblum, E. D. (1984). Academic procrastination: Frequency and cognitive-behavioral correlates. Journal of Counseling Psychology, 31, 503-509

Steel, P. D. G. (2002). A measurement and nature of procrastination. (Unpublished doctoral dissertation), University of Minnesota, Minnesota, USA.

Uzun Özer, B. (2011). A cross sectionel study on procrastination: Who procrastinates more? International Conference on Education, Research and Innovation, 18, 34-37. Singapore.

\section{Citation Information}

Aslan Efe, H. (2016) Fen Alanları Öğretmen Adaylarının Akademik Erteleme Davranışları ile Eğitim Teknolojilerine Yönelik Tutumları Arasındaki İlişki. Dicle Üniversitesi Ziya Gökalp Eğitim Fakültesi Dergisi, 28, 156-162. 